\title{
EDUCAÇÃO AMBIENTAL EM ESCOLAS PÚBLICAS DE SANTA INÊS (MA): MOBILIZANDO E CRIANDO
}

João Carlos de Araújo Furtado ${ }^{1}$

Alexsandra Maura Costa Bernal Martin²

Resumo: Em todo o mundo, as questões ambientais ocupam cada vez mais espaço na mídia, nas políticas públicas e nos processos econômico-produtivos. Mas, apesar de tamanha exposição e de diversos ganhos legais, os ambientes - naturais e construídos - continuam perdendo características que os qualificariam como equilibrados, capazes de oferecer qualidade de vida à população humana local e a todos os outros seres vivos. No universo escolar, as questões ambientais não são mais novidade; estão presentes de forma significativa pelo esforço de inúmeros professores, pela ação de muitas entidades e por sua importância essencial e urgente de nossa contemporaneidade. Este trabalho investigou como essas questões são abordadas em 07 (sete) escolas de Educação Básica no municipio de Santa Inês, Maranhão: estratégias, fontes de pesquisa, envolvimento do corpo docente e discente. Os resultados apontam como estratégias utilizadas para a quantificação de dados para saber o quadro de educação ambiental de cada escola.

Palavras-chave: Escolas; Santa Inês; Essencial; Urgente. 


\section{Introdução}

Entende-se por educação ambiental os processos por meio dos quais um indivíduo e a coletividade constroem valores sociais, conhecimentos, habilidades, atitudes e competências voltadas para a conservação do meio ambiente, bem de uso comum do povo, essencial à sadia qualidade de vida e a sua sustentabilidade. (Lei No 9.795/99 - Política Nacional de Educação Ambiental).

No universo escolar as questões ambientais não são mais novidade; estão presentes de forma significativa pelo esforço de inúmeros professores, pela ação de muitas entidades e por sua importância essencial e urgente de nossa contemporaneidade. Ademais, há três motivos que se articulam nos sistemas de ensino: a inclusão do meio ambiente na Constituição de 1988 como responsabilidade de todos em mantê-lo vivo e saudável; a promulgação das Políticas Nacionais de Educação Ambiental (Lei $N^{\circ}$ 9.795/99) e de Meio Ambiente (Lei $n^{\circ} 6.938 / 81$ ) que preveem a promoção da Educação Ambiental em todos os níveis e modalidades de ensino e em outros espaços sociais não formais; e ainda, a reorientação curricular produzida pelo MEC/SEF por meio dos Parâmetros Curriculares Nacionais onde Meio Ambiente foi incluído como um Tema Transversal. Em nível de Estado temos o Código de Proteção do Meio Ambiente (Lei Estadual $n^{\circ}$ 5.405/92) que explicita a educação ambiental em diversos capítulos e artigos.

Santa Inês é uma cidade com cerca de 80 mil habitantes que já apresenta alguns problemas das "cidades grandes" como violência, assentamentos urbanos irregulares e desordenados, saneamento básico deficitário, elevada frota de veículos, etc. Dentre esses problemas não devemos pensar em meio ambiente somente como natureza. Violência, falta de perspectiva, falta de sonhos e uso de drogas. Isso é reflexo de falta de objetivos de vida, de uma causa pela qual lutar e, a Educação Ambiental pode entrar aí, dando a essas pessoas uma razão, um motivo pelo que lutar, pelo o que fazer, pelo que transformar o seu redor.

Por ser um processo participativo, em que o educando assume o papel de elemento central do processo de ensino/aprendizagem pretendido, participando ativamente do diagnóstico dos problemas ambientais e buscando soluções, este vai se tornando um agente transformador, desenvolvendo habilidades, através de uma conduta ética, condizente ao exercício da cidadania. O Brasil é o único país da América Latina que tem uma política nacional específica para a Educação Ambiental. Sem dúvida foi uma grande conquista e essa não se deu sem o esforço e persistência de centenas de ambientalistas.

Em meio a esse contexto, a escola precisa (re)conhecer-se como ente social capaz de influenciar e contribuir para minorar o quadro de degradação social e ambiental que atende. Os Parâmetros Curriculares Nacionais para o Ensino Fundamental apresentam Meio Ambiente, como um tema transversal, ou seja, deve perpassar todos os conteúdos, ser trabalhado em todas as

revista brasileira educação ambiental 
disciplinas, além de ser urgente e abrangente.

A escola é o espaço social e o local onde o aluno dará sequência ao seu processo de socialização. O que nela se faz, se diz e se valoriza representa um exemplo daquilo que a sociedade deseja e aprova. Comportamentos ambientalmente corretos devem ser aprendidos na prática, no cotidiano da vida escolar, contribuindo para a formação de cidadãos responsáveis.

O objetivo deste trabalho foi iniciar um diagnóstico, via amostragem, da Educação Ambiental e do tema Meio Ambiente nas Redes Públicas de Ensino do municipio de Santa Inês, identificando as linhas de pensamento correntes, as práticas pedagógicas adotadas, as ações positivas e de intervenção social realizadas pelas Unidades de Ensino, tendo sido aplicado em 07 (sete) escolas da rede pública de ensino, nos anos 2011 e 2013.

\section{Materiais e métodos}

A primeira etapa foi visitar as 07 (sete) escolas públicas indicadas pelos alunos bolsistas para apresentação do projeto. Em caso de aceite em participar do mesmo, foi feito agendamento para aplicação de um questionário elaborado com perguntas abertas e fechadas em número de 10 questões, a professores e alunos pré-selecionados pela coordenação pedagógica da escola.

Em 2011, foi realizado em 05 (cinco) escolas da rede estadual, a saber: CEEFM Neuza Bastos, CAIC Santa Inês, CEEFM Estado de Pernambuco, CEEFM Pe. Chagas, CEEFM Senador José Sarney. Já em 2013, na Escola Municipal Pedro Lima e na Escola Estadual C. E. Josué Montello.

A segunda etapa foi sistematizar as informações obtidas com os questionários, elaborar um relatório síntese e planejar a realização de rodas de conversa, oficinas e sessões de estudo nas escolas.

A terceira e última etapa foi, a partir das respostas dos questionários, realizar: sessões de estudo sobre temas como correntes da educação ambiental, conceitos e definições de Sociedade, Meio Ambiente, Natureza, Cidades, Sustentabilidade, Resíduos Sólidos, Legislação Ambiental; oficinas de reutilização e reaproveitamento de PET e papel e jardinagem; visita ao aterro de resíduos da cidade. As oficinas foram aplicadas somente com os alunos das escolas no qual o projeto foi aplicado no ano de 2013, citadas anteriormente.

Todas as sessões de estudo e oficinas ocorreram nas escolas selecionadas, com a utilização de datashow, vídeo educativo/documentário, textos, dinâmicas em duplas e equipes. 


\section{Resultados e discussões}

Foi elaborado um questionário direcionado aos professores, só que não houve uma resposta, pois, os mesmos demonstraram interesse mínimo em torno das questões ambientais. Um número insignificante de questionários foi respondido, explicando assim o motivo da não quantificação dos dados, tendo apenas a percepção dos alunos sobre como a educação ambiental presente em suas escolas.

Ao todo, 162 alunos responderam ao questionário, o que equivale a $100 \%$ de participação, cujos resultados seguem abaixo, em forma de gráficos e textos.

Quando se aborda o campo da educação ambiental, podemos dar conta de que, apesar de sua preocupação comum com o meio ambiente e do reconhecimento do papel central da educação para a melhoria da relação com este último, diferentes autores adotam diferentes discursos sobre a educação ambiental e propõem diversas maneira de conceber e praticar a ação educativa nesse campo. É em meio a essas discussões que surgem as diferentes correntes em educação ambiental. Neste trabalho utilizamos as correntes apresentadas por Sato e Carvalho (2005).

A noção de corrente refere-se aqui a uma maneira geral de conceber e de praticar a educação ambiental. Podem se incorporar a uma mesma corrente, uma pluralidade e uma diversidade de proposições. Por outro lado, uma mesma proposição pode corresponder a duas ou três correntes diferentes, segundo o ângulo o qual é analisada. No projeto executado, foram identificadas três correntes da educação ambiental, de acordo com os questionários aplicados nas escolas. As identificadas foram a corrente naturalista, a corrente conservacionista-recursista e a corrente sistêmica.

A corrente naturalista é centrada na relação com a natureza. $O$ enfoque educativo pode ser cognitivo, experiencial, afetivo, espiritual ou artístico. A tradição da corrente naturalista é certamente muito antiga, se considerarmos as "lições de coisas" ou a aprendizagem por imersão e imitação nos grupos sociais cuja cultura está estreitamente forjada na relação com o meio natural. Resumidamente está focada na concepção que o meio ambiente é de espaço natural.

A corrente conservacionista/recursista agrupa as proposições centradas na "conservação" dos recursos, tanto no que concerne à sua qualidade quanto à sua quantidade: a água, o solo, a energia, as plantas e os animais. Quando se fala de "conservação da natureza", como da biodiversidade, trata-se sobretudo, de uma natureza-recurso.

$\mathrm{O}$ enfoque sistêmico permite conhecer e compreender adequadamente as realidades e as problemáticas ambientais. A análise sistêmica possibilita identificar os diferentes componentes de um sistema ambiental e salientar as relações entre seus componentes como as relações entre os elementos biofísicos e os sociais de uma situação ambiental.

revista brasileira educação ambiental 
A falta de capacitação dos professores diante dos temas ambientais e ao mesmo tempo de trabalharem em equipe, faz com que a educação ambiental seja mal entendida e pouco utilizada em projetos e no cotidiano escolar. Assim a Educação Ambiental fica em geral restrita ao professor de geografia e biologia, e percebemos essa tendência que é reforçada pela inclusão, na maioria das vezes, deste tema somente nos livros de ciências (Figura 1):

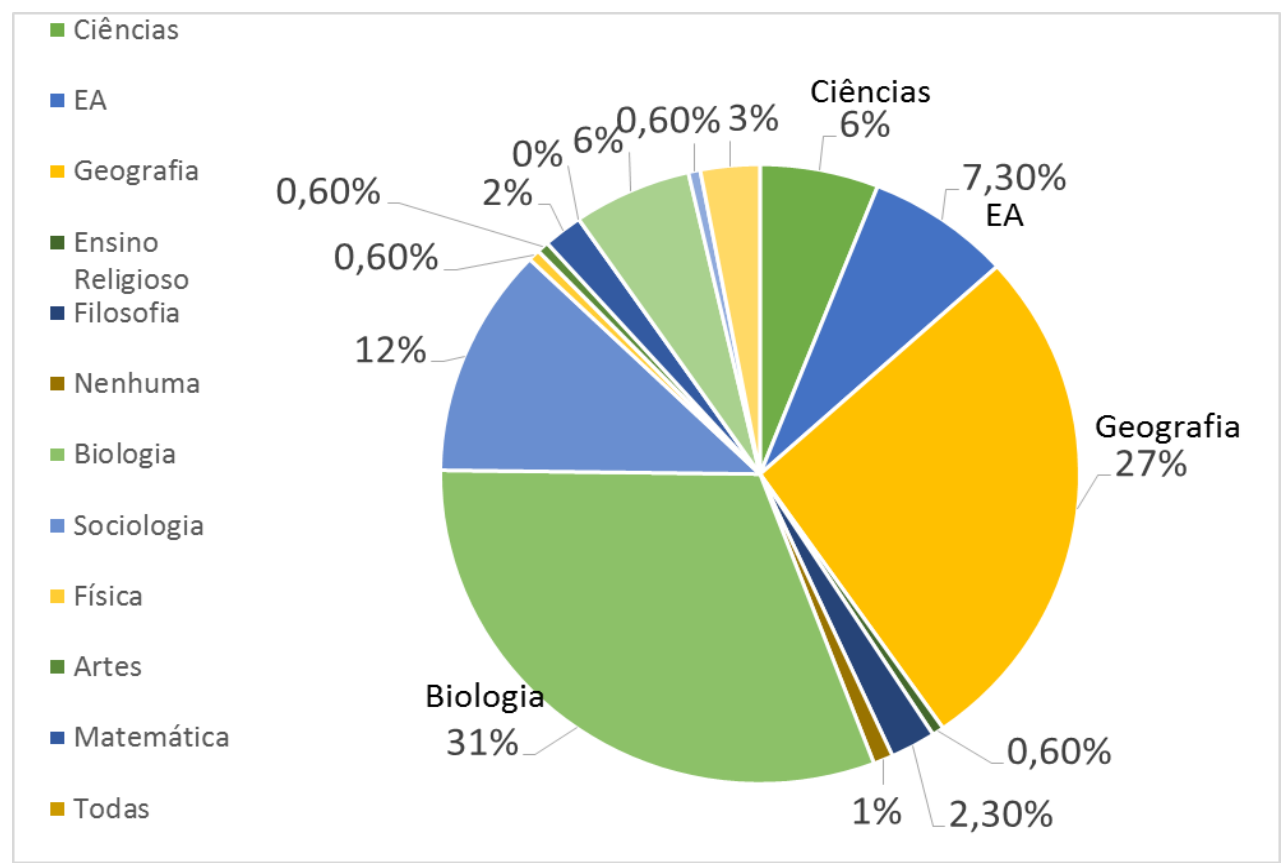

Figura 1: Disciplinas que incluem Educação Ambiental em seus conteúdos de sala de aula.

Conforme mostram as Figuras 2 e 3, quando indagados sobre o que seria a educação ambiental, os alunos não deram uma resposta aceitável para a pergunta em questão, a sua grande maioria disse que era só cuidar da natureza, ainda perguntados sobre o que a escola fazia para inserir a educação ambiental na rotina escolar, a resposta de maior percentual foi a esperada: nada.

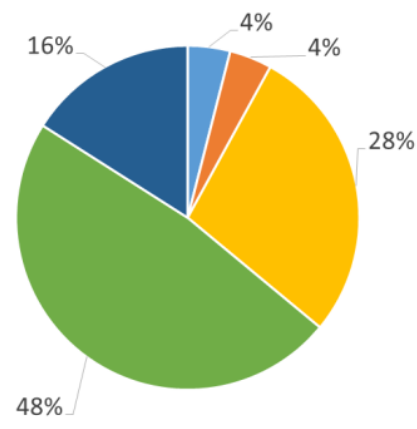

Figura 2 - Resultado da pergunta sobre o que seria educação ambiental.

Revbea, São Paulo, V. 11, № 1: 108-116, 2016.

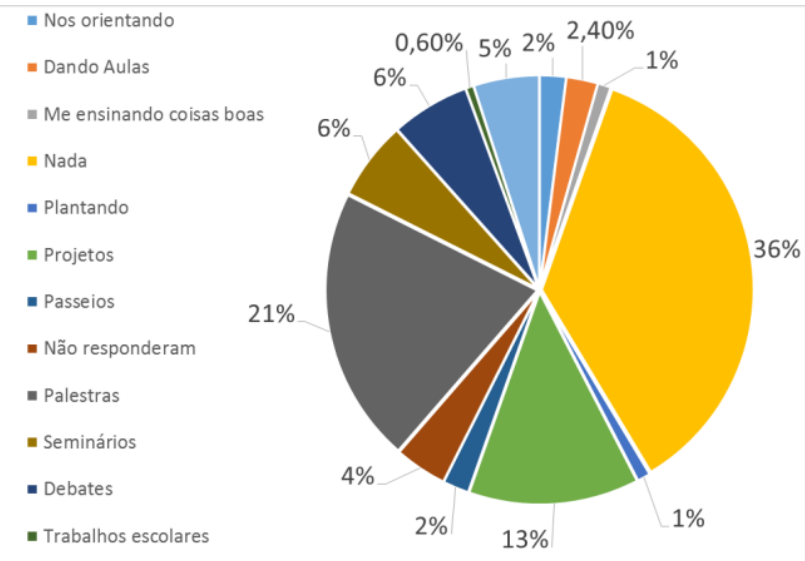

Figura 3 - Resultado da pergunta sobre açoes da escola para inserir a Educação Ambiental no cotidiano escolar. 
Como é possível observar, outras respostas foram dadas, como palestras, projetos, etc. Só que não inserindo na vida dos alunos o verdadeiro jeito de como a educação ambiental deve estar inserida na vida desses alunos.

Segundo Vasconcellos (1997), a presença, em todas as práticas educativas, da reflexão sobre as relações dos seres entre si, do ser humano com ele mesmo e do ser humano com seus semelhantes é condição imprescindível para que a Educação Ambiental ocorra. Dentro desse contexto, sobressaem-se as escolas, como espaços privilegiados na implementação de atividades que propiciem essa reflexão, pois isso necessita de atividades de sala de aula e atividades de campo, com ações orientadas em projetos e em processos de participação que levem à autoconfiança, à atitudes positivas e ao comprometimento pessoal com a proteção ambiental implementados de modo interdisciplinar (DIAS, 1992).

É possível notar como mostram as Figuras 4 e 5, que os alunos têm um verdadeiro interesse pelas questões ambientais e que acham necessária a implantação da educação ambiental no universo escolar.

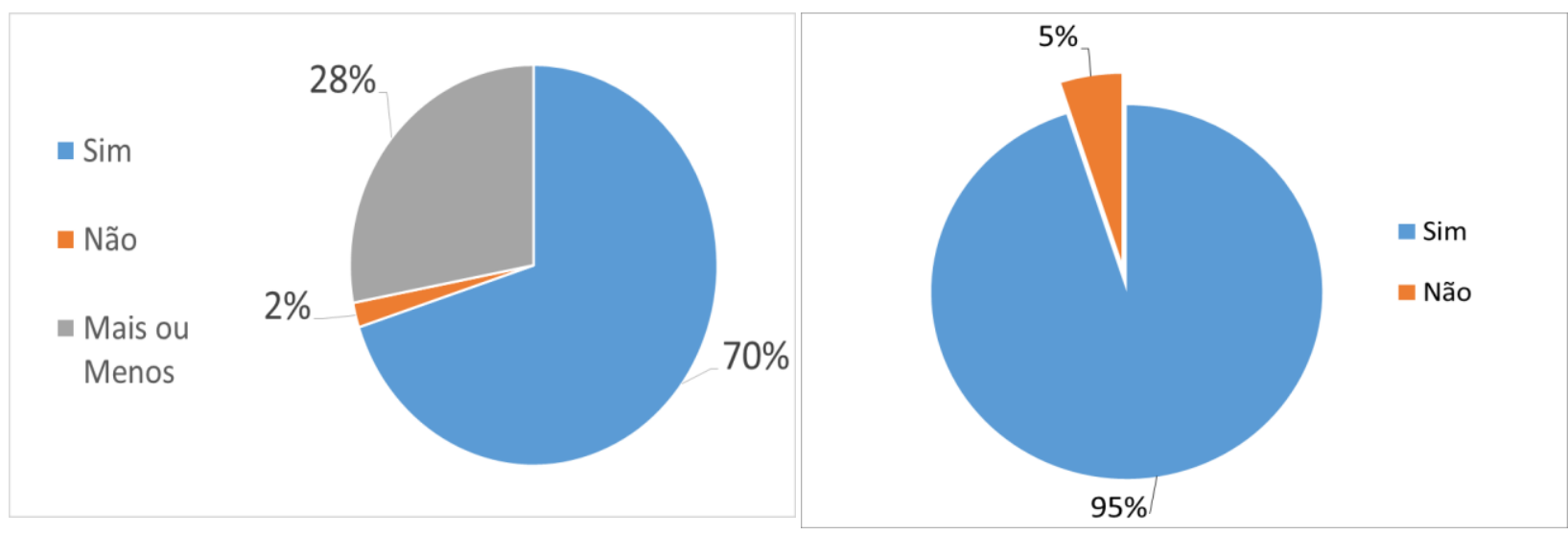

Figura 4: Resultado da pergunta sobre o interesse dos alunos nas questões ambientais.

Figura 5: Resultado da pergunta se os alunos acham necessário a EA.

No ensino fundamental a educação ambiental se encontra mais presente, mas apenas como uma única matéria, não havendo a transversalidade como já foi falada anteriormente. No ensino médio a situação já é bem diferente, não se nota a educação ambiental sendo inserida nas matérias ministradas. Ela aparece apenas algumas vezes dentro dos assuntos debatidos durantes as aulas de biologia. As escolas deveriam estar sempre abertas a projetos de educação ambiental que tenham inspiração e iniciativa extra escolar (nas comunidades, em órgãos governamentais de todas as instâncias, nas entidades não-governamentais etc.) e, ao mesmo tempo também a escola deve ser palco de iniciativas que extrapolem seus limites e se irradiem para as comunidades do entorno ou mais afastadas.

Em uma última pergunta sobre o que seria meio ambiente, como mostra Revbea, São Paulo, V. 11, № 1: 108-116, 2016.

revista brasileira educação ambiental 
a Figura 6, os alunos na sua maioria demonstraram não ter a noção do que seja meio ambiente, outros dizem que meio ambiente é apenas o habitat de seres vivos, sendo que meio ambiente é um conjunto de unidades ecológicas que funcionam como um sistema natural, e incluem toda a vegetação, animais (incluindo o homem), microrganismos, solo, rochas, atmosfera e fenômenos naturais que podem ocorrer em seus limites.

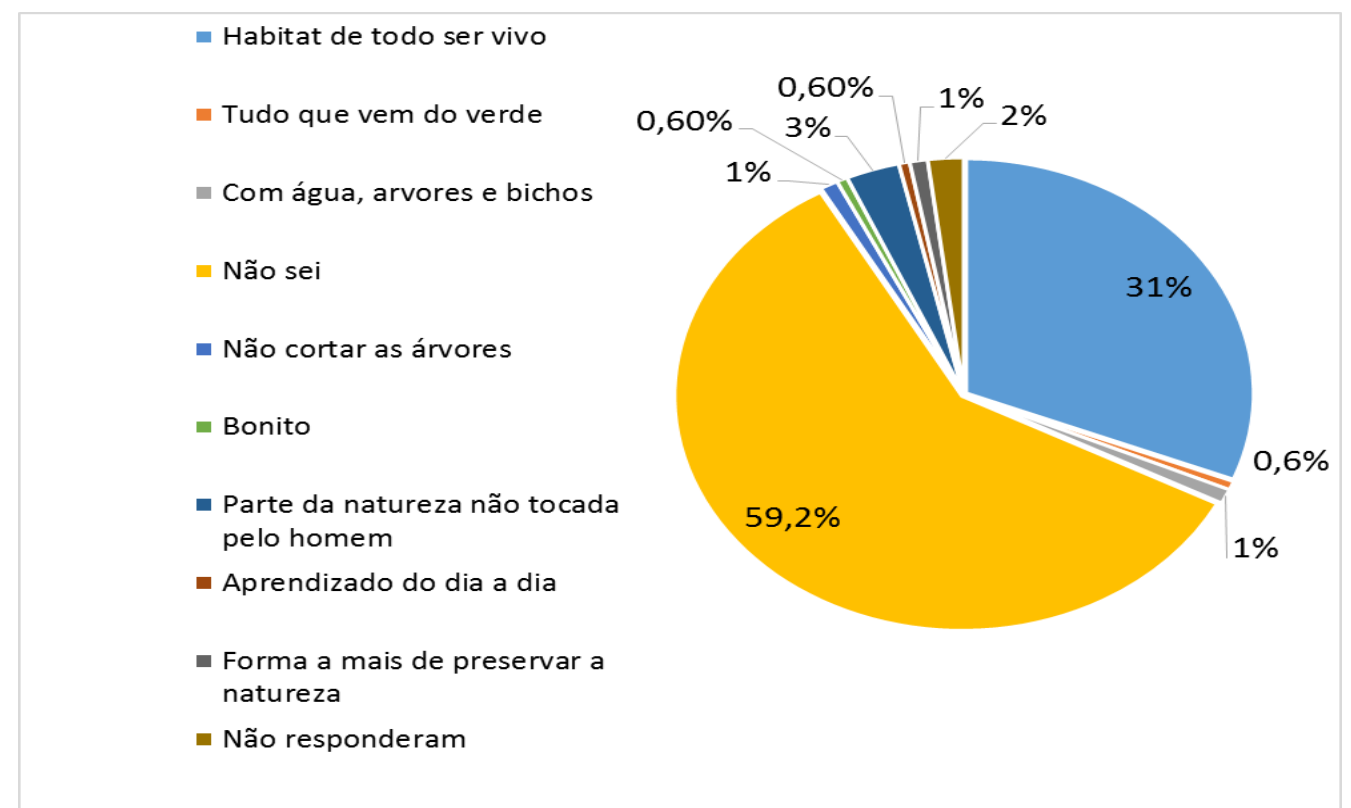

Figura 6: Respostas dos alunos quando questionados sobre o que seria meio ambiente.

As Figuras 7, 8 e 9 a seguir ilustram momentos diferentes da execução do projeto:

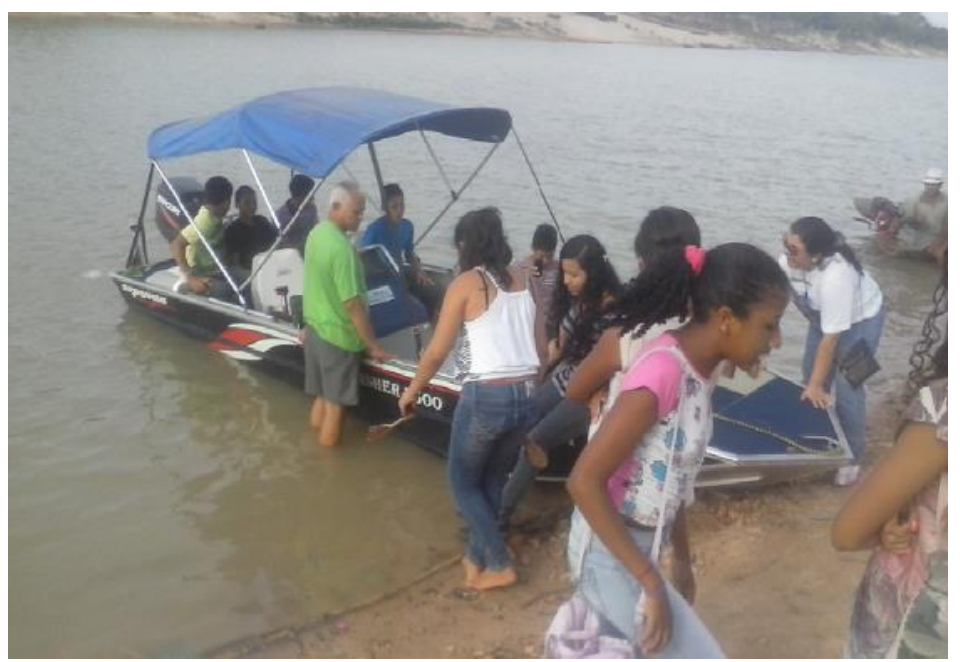

Figura 7: Visita com alunos ao Rio Pindaré. 


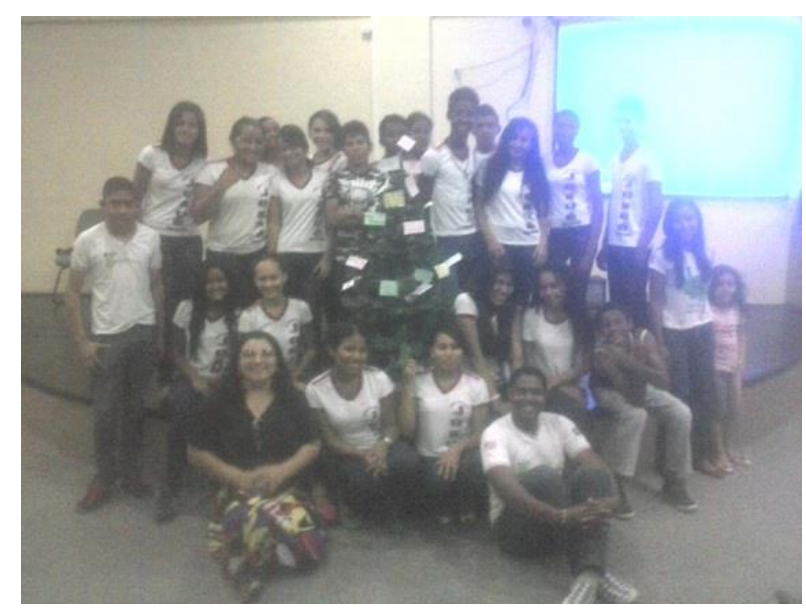

Figura 8: Momento de encerramento com alguns alunos no Instituto Federal.

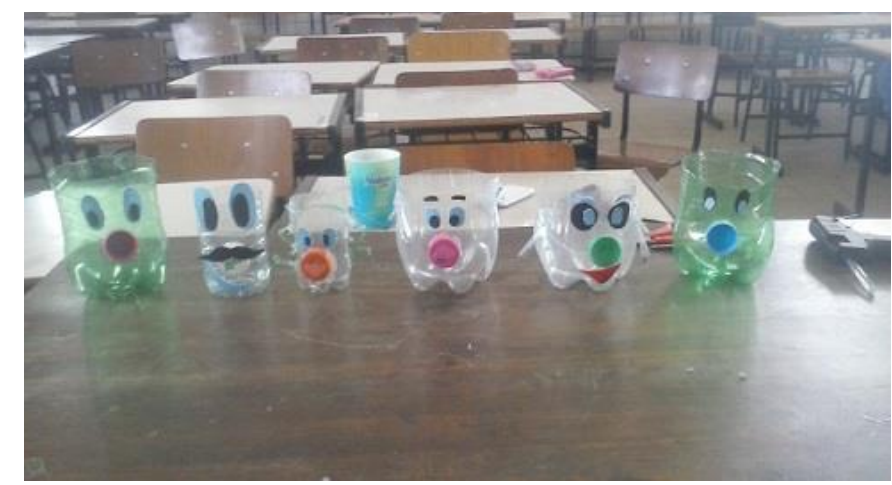

Figura 9: Resultado de oficina sobre reciclagem com garrafas PET.

Implementar a Educação Ambiental nas escolas tem se mostrado uma tarefa exaustiva. Existem grandes dificuldades nas atividades de sensibilização e formação, na implantação de atividades e projetos e, principalmente, na manutenção e continuidade dos já existentes. Segundo Andrade (2000),

... fatores como o tamanho da escola, número de alunos e de professores, predisposição destes professores em passar por um processo de treinamento, vontade da diretoria de realmente implementar um projeto ambiental que vá alterar a rotina na escola, etc, além de fatores resultantes da integração dos acima citados e ainda outros, podem servir como obstáculos à implementação da Educação Ambiental.

Dado que a Educação Ambiental não se dá por atividades pontuais, mas por toda uma mudança de paradigmas que exige uma contínua reflexão e apropriação dos valores que remetem a ela, as dificuldades enfrentadas assumem características ainda mais contundentes. 


\section{Conclusão}

O resultado do projeto aponta para um avanço na concepção de meio ambiente, diante da inclusão da corrente sistêmica nas respostas dos alunos. No entanto, é possível perceber ainda a existência da educação ambiental apenas como uma disciplina para conscientizar, o que demonstra que os alunos não desenvolveram as suas potencialidades e também não adotaram posturas pessoais e comportamentos sociais construtivos, não colaborando para a construção de uma sociedade socialmente justa, em um ambiente saudável.

Os professores têm noção de que Educação Ambiental e Meio Ambiente não são a mesma coisa, porém, não sabem apontar as diferenças. Os alunos aceitam a Educação Ambiental como disciplina e é muito mais trabalhada em Biologia e Geografia.

Segundo os Parâmetros Curriculares Nacionais (PCN) a escola tem a obrigatoriedade de integrar a educação ambiental no ensino por meio da transversalização, e isso foi praticamente imperceptível. A proposta dos PCNs é de uma abordagem ambiental integrada, tanto entre as disciplinas como entre a sociedade seus problemas específicos. A vantagem de uma abordagem assim é a possibilidade de uma visão mais integradora e melhorada na compreensão das questões socioambientais como um todo.

\section{Referências}

ANDRADE, D.F. Implementação da Educação Ambiental em escolas: uma reflexão. Revista Eletrônica do Mestrado em Educação Ambiental, v. 4.out/nov/dez 2000.

BRASIL. Constituição (1981). Lei no 6.938, de 31 de agosto de 1981. Política Nacional do Meio Ambiente. 1. ed. Brasília, DF, 31 ago. 1981

BRASIL. Constituição (1999). Lei no 9.975, de 27 de abril de 1999. Dispõe sobre a educação ambiental, institui a Política Nacional de Educação Ambiental e dá outras providências.. Política Nacional de Educação Ambiental: Legislação Federal. 1. ed. Brasília, DF, 27 abr. 1999.

DIAS, G.F. Educação Ambiental: princípios e práticas. 8 ed. São Paulo: Gaia, 2003.

ESTADO DO MARANHÃO. Constituição (1997). Lei № № 5.405, de 08 de abril de 1992. Código de Proteção de Meio Ambiente do Estado do Maranhão. 3. ed. SÃO LUIS, MA, 08 abr. 1992.

SATO, M; CARVALHO, I.C.M (orgs). Educação Ambiental: Pesquisa e Desafios. Porto alegre: Artmed. 2005. 232p.

VASCONCELLOS, H.S.R. A pesquisa-ação em projetos de Educação Ambiental. In: PEDRINI, A. G. (org). Educação Ambiental: reflexões e práticas contemporâneas. Petrópolis, Vozes, 1997. 